\title{
Optimum Conditions For The Synthesis of High SolubilityCarboxymethyl Chitosan
}

Mardiyah Kurniasih*, Purwati, Dadan Hermawan and Muhamad Zaki

Department of Chemistry, Faculty of Science and Engineering, Jenderal Soedirman University, 53123 Purwokerto, Indonesia *Corresponding Author: m_kurniasih@yahoo.com

\section{Article history :}

Received 2 August 2014

Revised 9 September 2014

Accepted 28 Septmeber 2014

Available online 8 October 2014

\section{GRAPHICAL ABSTRACT}

$\mathrm{HO}_{\mathrm{HO}}^{\left.\mathrm{CH}_{2} \mathrm{COOH}\right)_{2}}$

\section{ABSTRACT}

A research on optimizing the synthesis conditionsto obtaincarboxymethyl chitosan with the highest solubility in $1 \%(\mathrm{v} / \mathrm{v})$ acetic acid as a solvent have been performed. Optimization was performed by varying: the concentration of $\mathrm{NaOH}$ during alkalizing the chitosan, chitosan: monochloroacetic acidratio, temperature and reaction time. This study uses a full factorial experimental design. The results showed that the highest solubility was found in $40 \%(\mathrm{w} / \mathrm{v}) \mathrm{NaOH}$ concentration, chitosan to monochloroacetic acid ratio of $1: 7$, reaction temperature of $80^{\circ} \mathrm{C}$ and reaction time at 4 hours with the solubility up to $63.78 \mathrm{mg}$ $/ \mathrm{mL}$. The IR and NMR $\left({ }^{1} \mathrm{H}\right.$ and $\left.{ }^{13} \mathrm{C}\right)$ spectra confirmed the success of the synthesis. The results of water content, ash content, molecular weight and swelling effect of carboxymethyl chitosan at the highest solubility were $14.27 \%, 8.48 \%, 2.8678 \times 10^{5} \mathrm{~g} / \mathrm{mol}$ and $884.19 \%$, respectively.

Keywords: synthesis, solubility, carboxymethyl chitoan

(C) 2014 Penerbit UTM Press. All rights reserved http://dx.doi.org/10.11113/mjfas.v10n4.277

\section{INTRODUCTION}

Chitosan (Figure 1) is a polysaccharide derived from chitin, a linear chain of acetylglucosamine groups, generally extracted from crab shell or squid pen [1]. Chitosan hasbeen used in many industries including wastewater treatment, medicine, food, and cosmetics [2]. Chitosan is widely used in various fields because it has properties of hydrophilicity, biocompatibilityand biodegradability [3]. The amino groups of chitosan are weak bases which predominantly protonated when $\mathrm{pH}<\mathrm{pKa} \approx 6.5$, leading to the solubilization of the polymer only in dilute acid solutions. However, the poor solubility of chitosan when $\mathrm{pH}>6.5$ is a serious drawback in many of its applications. Thus, the preparation of chitosan derivatives has been envisaged to overcome its limited solubility in aqueous media [4].

Carboxymethyl chitosan, which is a water-soluble chitosan derivative, has attracted much attention as it widened its application fields. Beside good solubility in water, carboxymethyl chitosan has unique chemical, physical and biological properties such as high viscosity, large hydrodynamic volume, low toxicity, biocompatibility and good ability to form films, fibers and hydrogels. Carboxymethyl chitosan (Figure 2) was prepared by etherification some of the hydroxyl of $-\mathrm{CH}_{2} \mathrm{OH}$ groups as $\mathrm{OCH}_{2} \mathrm{COOH}$. By doing this, the reactive ligands such as $\mathrm{COOH}$ and $-\mathrm{NH}_{2}$ groups are still amenable to chemical modifications to improve its physical properties for metal chelation and dye binding [5].

The properties and applications of carboxymethyl chitosanare strongly dependent on its structural characteristics [4]. Some factors that influence the formation of carboxymethyl chitosanare the quality of the chitosan, the amountofalkali chitosan obtained (alkalizing process), monochloroacetic acid concentration, and the etherification temperature [6].Thus, the aim of this work was to vary the concentration of $\mathrm{NaOH}$, ratio of chitosan to monochloro acetic acid, temperature and etherification time in order to obtain the optimum conditions for the synthesis of carboxymethyl chitosan with high solubility.

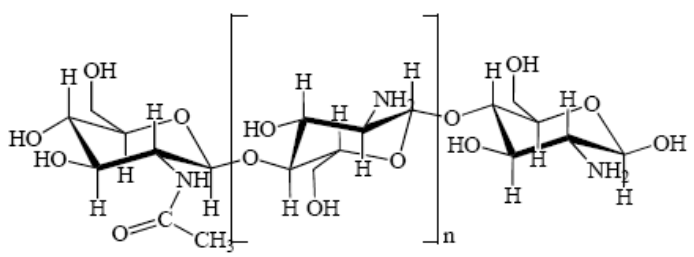

Figure 1.Chemical structure of chitosan.

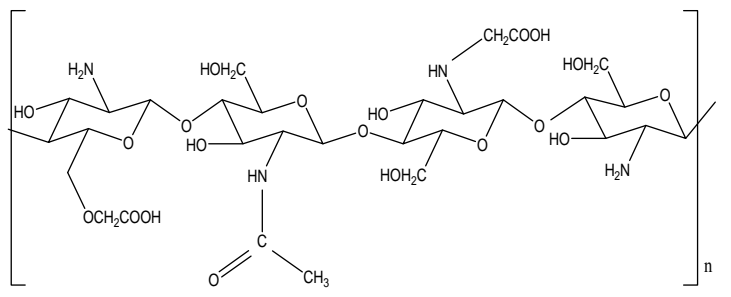

Figure 2. Chemical structure of N,O-carboxymethyl chitosan 


\section{EXPERIMENTAL}

Materials.

Materials used in this study are sodium chloride, acetic acid, methanol, and monochloroacetic acid were purchased from Merck Co. Chitosan with the degree of deacetylation value of $89.75 \%$ was synthesized from shrimps, distilled water, universal $\mathrm{pH}$ meter, and phosphate buffer $\mathrm{pH}$ 7.4. All chemicals and reagents used in the experiment were of analytical grade. The instruments used in this study were glass tools, analytical balance, oven, electric cooker, filter paper, watch glass, clamps, thermometers, hotplatestirrer, Shimadzu 8201 FTIR spectrophotometer, and Agilent $500 \mathrm{MHz}{ }^{1} \mathrm{H}-\mathrm{NMR}$ and $125 \mathrm{MHz}{ }^{13} \mathrm{C}-\mathrm{NMR}$ spectrophotometer.

\section{Synthesis of carboxymethyl chitosan.}

Chitosan was basified using $\mathrm{NaOH}$ with concentration variation of $40 \%, 50 \%$, and $60 \%(\mathrm{w} / \mathrm{v})$. Monochloroacetic acid was then added into the solution with variation of the ratio of chitosan to monochloroacetic acid of 1:3, 1:5, and 1:7 and stirred for 2, 3 and 4 hours at a temperature of 70 , and $80{ }^{\circ} \mathrm{C}$ for each mixture. The mixture was then neutralized with $10 \%$ acetic acid, and poured into an excess solution of $70 \%$ methanol. The mixture was then filtered and washed using methanol. The precipitate obtained was dried at $55^{\circ} \mathrm{C}$.

\section{Solubility test of carboxymethyl chitosan in $1 \%(\mathrm{v} / \mathrm{v})$ acetic} acid.

A $100 \mathrm{mg}$ carboxymethyl chitosan was inserted into a glass beaker, and $1 \%$ acetic acid was added to it slowly to dissolve the carboxymethyl chitosan completely. Solubility of carboxymethyl chitosan calculated as below:

Carboxymethyl chitosan solubility $(\mathrm{w} / \mathrm{v})=\frac{\mathrm{m}}{\mathrm{v}}$

Description:

$\mathrm{m}=$ weight of carboxymethyl chitosan (mg)

$\mathrm{v}=$ volume of solvent $(\mathrm{mL})$

Statistical test on the solubility of carboxymethyl chitosan in $1 \%$ acetic acid.

This study used a full factorial experimental design with 4 factors. Factor $\mathrm{A}$ (concentration of $\mathrm{NaOH}$ ) has three levels, namely $40 \%, 50 \%$, and $60 \%(\mathrm{w} / \mathrm{v})$. Factor B (ratio of chitosan: monochloroacetic acid) has three levels: 1:3, $1: 5$, and 1:7. Factor $\mathrm{C}$ (temperature) with two levels, namely $70{ }^{\circ} \mathrm{C}$, and $80{ }^{\circ} \mathrm{C}$ and factor $\mathrm{D}$ (time) has three levels: 2, 3, and 4 hours. Carboxymethyl chitosan produced through the above treatment was tested for their solubility in $1 \%(\mathrm{v} / \mathrm{v})$ acetic acid as a solvent. The solubility data obtained were then statistically tested using analysis of variance for factors $\mathrm{A}, \mathrm{B}, \mathrm{C}$ and $\mathrm{D}$ to determine the effect of each factor on the solubility of carboxymethyl chitosan. The result of analysis of variance was further examined using Least Significant Difference (LSD) test.

\section{Characterization of carboxymethyl chitosan.}

Characterization performed on the synthesized carboxymethyl chitosan with the highest solubility including structural characterization and physical studies. FTIR, ${ }^{1} \mathrm{H}-\mathrm{NMR}$ and ${ }^{13} \mathrm{C}-\mathrm{NMR}$ used to structural characterization. While for physical studies include water content, ash content, molecular weight, porosity, and swelling effect.

\section{RESULT AND DISCUSSION}

\section{Synthesis of Carboxymethyl Chitosan.}

This study was conducted to obtain the optimum conditions for the synthesis of carboxymethyl chitosan with high solubility in water. Therefore, various types carboxymethyl chitosan were made with various concentration of $\mathrm{NaOH}$, ratio of chitosan to monochloro acetic acid, temperature and etherification time. Variations of such treatment produced 54 types carboxymethyl chitosan. Based on the results, \% of yield of carboxymethyl chitosan ranged from 14.89 to $56.82 \%$ with the highest values found in the type carboxymethyl chitosan Y37 (with $40 \%(\mathrm{w} / \mathrm{v}) \mathrm{NaOH}$ concentration, ratio of chitosan: monochloroacetic acid of $1: 3$, and a reaction time of 4 hour at a temperature of $70^{\circ} \mathrm{C}$.

In the synthesis process of carboxymethyl chitosan, chitosan binds to $\mathrm{Na}^{+}$from $\mathrm{NaOH}$ during basified. Then chitosan alkali reacts with monochloroacetic acid causes an ions exchange. $\mathrm{Na}^{+}$ions that are easily dissolved in water will bound $\mathrm{Cl}^{-}$ions that are released by monochloroacetic acid forming a salt solution of $\mathrm{NaCl}$. Meanwhile chitosan that has been releasing $\mathrm{Na}^{+}$ions will be reactive against the carboxyl group of the monochloroacetic acid thus forming carboxymethyl chitosan [6].

Solubility Test of Carboxymethyl Chitosan in $1 \%(\mathrm{v} / \mathrm{v})$ Acetic Acid.

The results of carboxymethyl chitosan solubility test with a concentration of $40 \%(\mathrm{w} / \mathrm{v}) \mathrm{NaOH}$ (Figure 3 ) shows that the solubility of carboxymethyl chitosan tends to fall with increasing ratio of chitosan to monochloroacetic acid except for carboxymethyl chitosan that was reacted for $4 \mathrm{~h}$ at $80{ }^{\circ} \mathrm{C}$. The decrease of carboxymethyl chitosan solubility may be due to the excess of monochloroacetic acid resulting in further hydrolysis to form sodium-glycolic [6]. On the other hand, the increase in the solubility of carboxymethyl chitosan that was reacted for $4 \mathrm{~h}$ at $80^{\circ} \mathrm{C}$ might be due to the increasing amount of monochloroacetic acid substituted into chitosan thereby increasing the solubility. 
Solubility test of carboxymethyl chitosan with $\mathrm{NaOH} 50 \%(\mathrm{w} / \mathrm{v})$ (Figure 4) shows that the solubility tend to increase with increasing ratio of chitosan to monochloroacetic acid. According to previous study [6], the higher concentration of monochloroacetic acid was added, the higher the solubility. The length of reaction time also contributes to the increasing solubility of carboxymethyl chitosan. This is because the longer the reaction time, the higher the amount of monochloro acetic acid reacted with chitosan. Figure 4 also shows that carboxymethyl chitosan that was reacted at $80{ }^{\circ} \mathrm{C}$ has a higher solubility than the carboxymethyl chitosan reacted at $70^{\circ} \mathrm{C}$. Rising temperatures cause the rate of reaction between chitosan and monochloroacetic acid so that more chitosan is substituted.

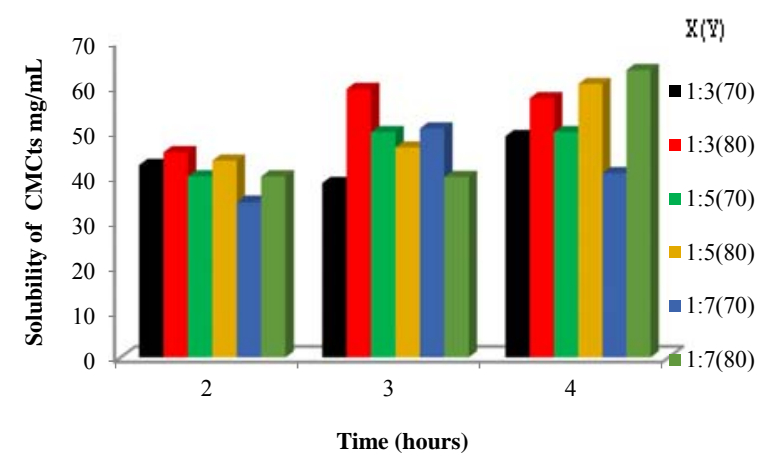

Figure 3. Solubility of carboxymethyl chitosan at $\mathrm{NaOH}$ $40 \%(\mathrm{w} / \mathrm{v})$

Remark:

$\mathrm{X}=$ Ratio of Chitosan vs. monochloroacetic acid (w/w) $\mathrm{Y}=$ temperature $\left({ }^{\circ} \mathrm{C}\right)$

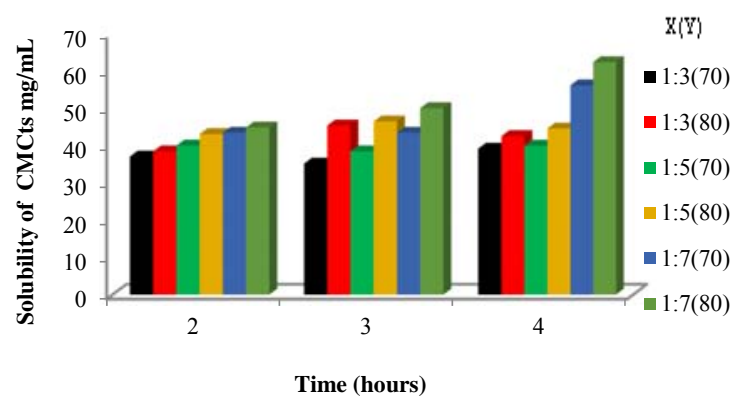

Figure 4. The solubility of carboxymethyl chitosan at $\mathrm{NaOH} 50 \%(\mathrm{w} / \mathrm{v})$

Remark:

$\mathrm{X}=$ Ratio of Chitosan vs. monochloroacetic acid (w/w) $\mathrm{Y}=$ temperature $\left({ }^{\circ} \mathrm{C}\right)$

Solubility test of carboxymethyl chitosan with $\mathrm{NaOH} 60 \%(\mathrm{w} / \mathrm{v}$ ) (Figure 5) did not vary much compared with solubility of chitosan with $\mathrm{NaOH} 50 \%$ (w/v). The solubility tend to rise with the increase in the ratio of chitosan and monochloroacetic acid used. The solubility of carboxymethyl chitosan with $\mathrm{NaOH} 60 \%$ (w/v) reacted at $80^{\circ} \mathrm{C}$ and heated at 4 hours was found to be lowered with the one reacted at $70{ }^{\circ} \mathrm{C}$. This is due to the high concentration of $\mathrm{NaOH}$ with long reaction times and high temperatures because the remaining $\mathrm{NaOH}$ compete with $\mathrm{Cl}^{-}$ions from the monochloroacetic acid to produce chemical salts such as sodium chloride and sodium glycosides [6]. Based on Figure 3, 4, and 5 it can be seen that the highest solubility of carboxymethyl chitosan obtained in $40 \%(\mathrm{w} / \mathrm{v})$ alkalizing conditions, chitosan: monochloroacetic acid ratio $1: 7$, temperature and reaction time, 4 hours at $80^{\circ} \mathrm{C}$, respectively.

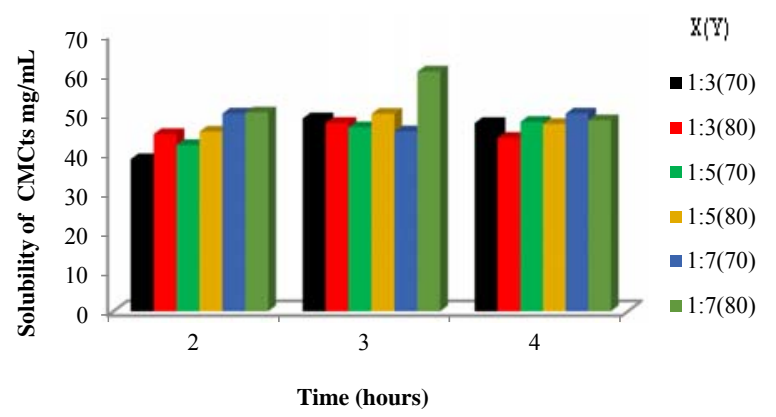

Figure 5. The solubility of carboxymethyl chitosan at $\mathrm{NaOH} 60 \%(\mathrm{w} / \mathrm{v})$

Remark:

$\mathrm{X}=$ Ratio of Chitosan vs. monochloroacetic acid (w/w)

$\mathrm{Y}=$ temperature $\left({ }^{\circ} \mathrm{C}\right)$

Statistic Test on the Solubility of Carboxymethyl Chitosan in $1 \%(v / v)$ Acetic Acid

Result of the analysis of variance shows that there is no differences in the overall factor of carboxymethyl chitosan solubility in $1 \%(\mathrm{v} / \mathrm{v})$ acetic acid solvent except on the interaction between chitosan and temperature. This is because all of these factors have a significance value of less than 0.05 , while for the interaction of chitosan with temperature; the significance value is 0.07 .

A further testing is performed using the least significant difference (LSD) method. LSD test was conducted to determine which treatments significantly different and which treatments that is not different. BNT analysis results on the concentration of $\mathrm{NaOH}$ shows that there are two significantly different pairs of treatments that are $\mathrm{NaOH} 40 \%$ and $50 \%(\mathrm{w} / \mathrm{v})$, with a Mean Difference coefficient of 3.4806 and $\mathrm{NaOH} 60 \%$ and $50 \%(\mathrm{w} / \mathrm{v})$, with a coefficient of Mean Difference 3.5508. This is because the second pair of treatmenthas a significance value of count less than 5\% error level. While, $\mathrm{NaOH} 40 \%$ and $60 \%(\mathrm{w} / \mathrm{v})$ treatment pair do not have a significant difference, with aMean Difference coefficient of 0.0703 and a significance of count 0.859 .

The LSD of time and ratio of chitosan to monochloroacetic acid shows that each sample pair has a 
significantly different effect on the solubility of carboxymethyl chitosan in $1 \%(\mathrm{v} / \mathrm{v})$ acetic acid.Thesignificant value calculated for all pairs is less than $5 \%$ error level.

\section{Characterization of Carboxymethyl Chitosan FTIR and NMR Characterization}

FTIR analysis results are as presented in Figure 6. In general, the IR spectra of chitosan and carboxymethyl chitosan show similar peaks. The absorption at wave numbers of $2885 \mathrm{~cm}^{-1}$ shows the symmetry of the $\mathrm{CH}$ ring, $-\mathrm{CH}_{3}$ and $-\mathrm{CH}_{2}-$ stretching vibration. The absorption at wave number $1000-1300 \mathrm{~cm}^{-1}$ shows the cyclic ether and glycosides bond. Carboxymethyl chitosan formation is indicated by the shift of the stretching absorption peak of $\mathrm{C}=\mathrm{O}$ groups at $1597 \mathrm{~cm}^{-1}$ in the IR spectra of chitosan to $1604 \mathrm{~cm}^{-1}$ in the IR spectra carboxymethyl chitosan. According to Mourya et al., [7], the absorption peak at
1597 to 1650 shows that the $\mathrm{C}=\mathrm{O}$ groups are overlapping with $\mathrm{N}-\mathrm{H}$ bending. In addition, the peak shifts also ccurred in the absorption peak of hydroxyl group at $3448 \mathrm{~cm}^{-1}$ in the IR spectra of chitosan to $3425 \mathrm{~cm}^{-1}$ in the IR spectra of carboxymethyl chitosan. Both of these peaks are evidence of the formation carboxymethyl chitosan.

To support the FTIR data, the ${ }^{1} \mathrm{H}$ and ${ }^{13} \mathrm{C}$-NMR spectroscopy analysis on high solubility carboxymethylchitosan was performed. Before etherification reaction, the ${ }^{1} \mathrm{H}-\mathrm{NMR}$ spectrum of chitosan shows the signal centered at $\delta \cong 2.00 \mathrm{ppm}$ corresponds to the hydrogens of the methyl moieties belonging to the acetamido groups, the signal between 3.10 and $2.90 \mathrm{ppm}$ corresponds to the hydrogen bonded to the $\mathrm{C} 2$ glucosamine ring, while the signals between 3.30 and $4.00 \mathrm{ppm}$ correspond to hydrogens bonded to the carbon atoms $\mathrm{C} 3$, C4, C5 and C6 of the glucopyranose that are overlapped [4].

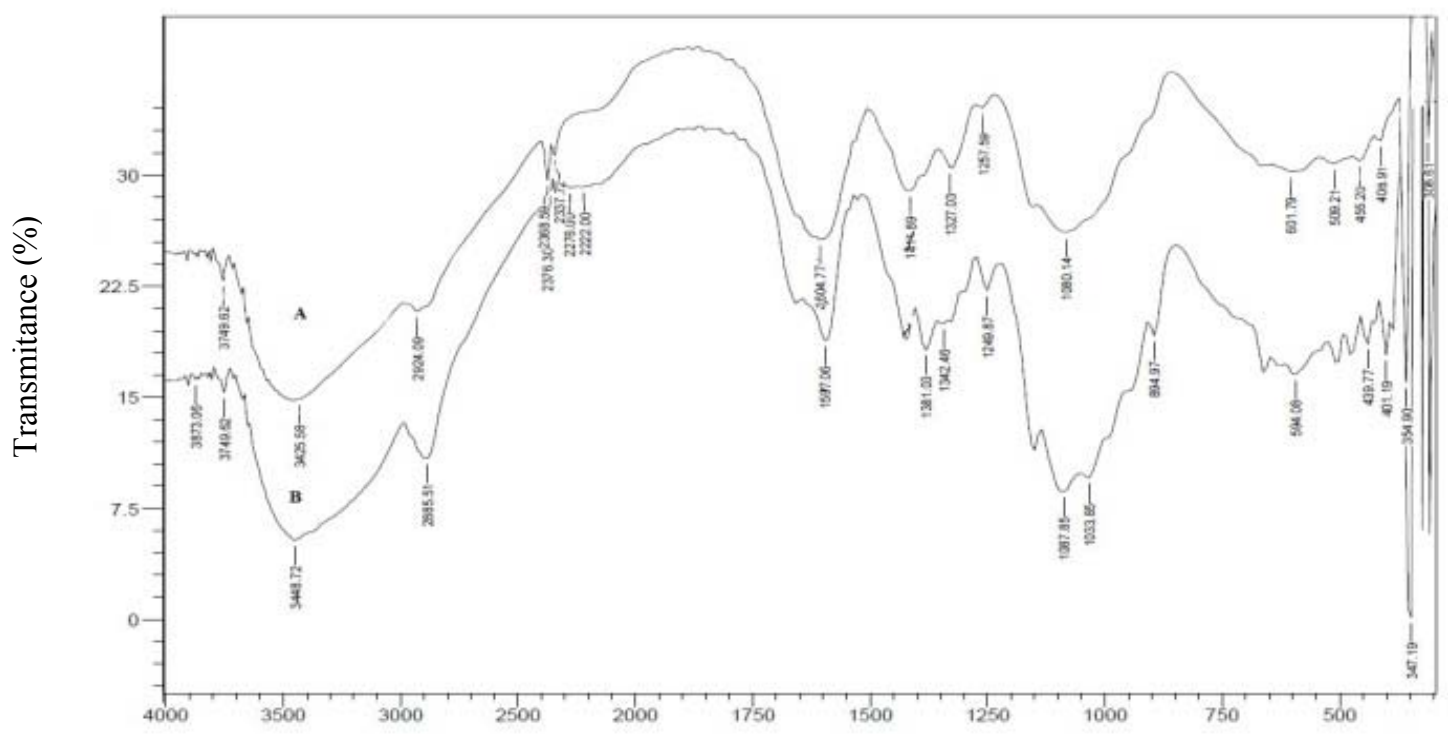

Figure 6. IR spectra of carboxymethyl chitosan (A) and Wave Number $\left(\mathrm{cm}^{-1}\right)$

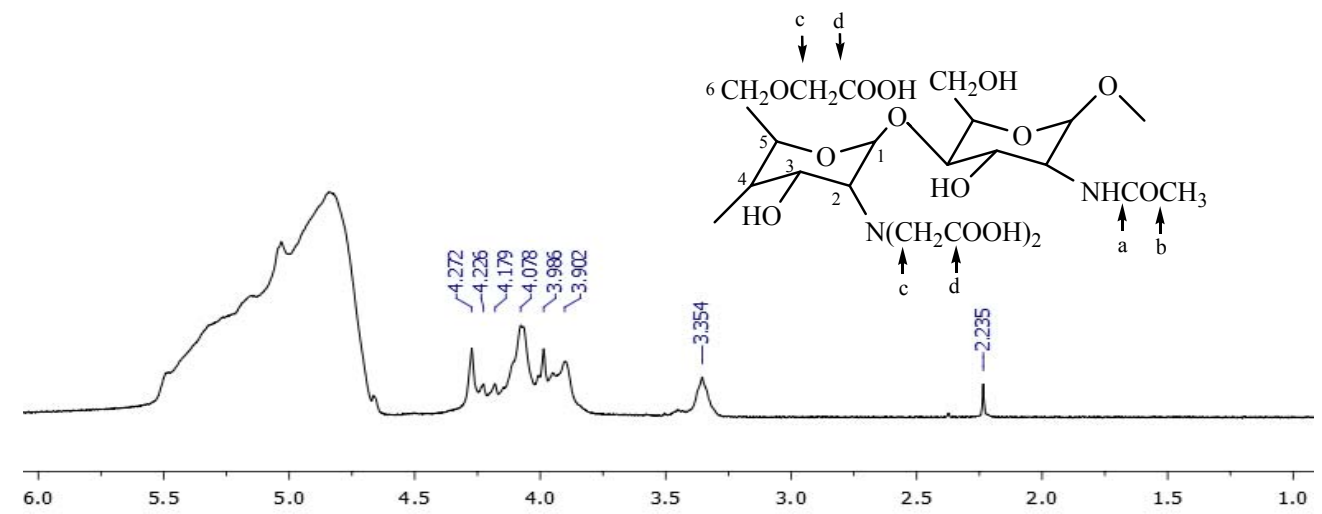

Figure $7 .{ }^{1} \mathrm{H}-\mathrm{NMR}$ spectra of carboxymethyl chitosan 


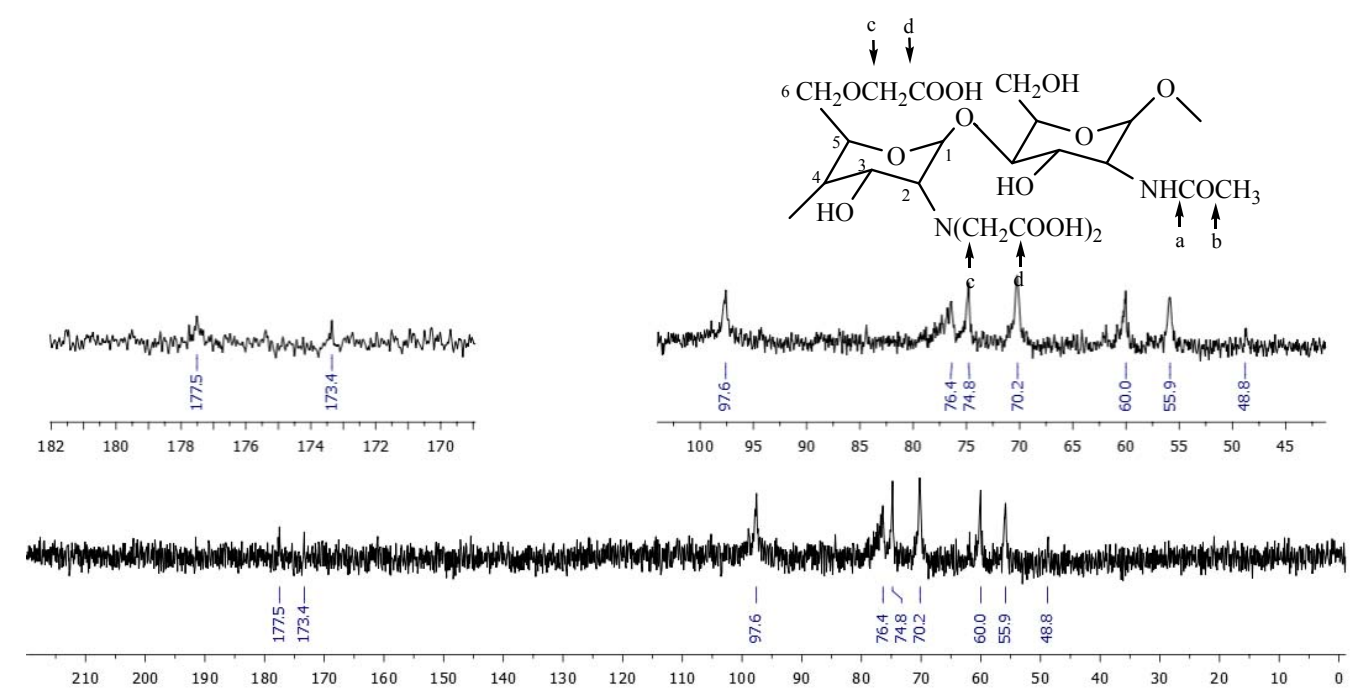

Figure $8 .{ }^{13} \mathrm{C}-\mathrm{NMR}$ Spectrum of carboxymethyl chitosan

After etherification reaction, the ${ }^{1} \mathrm{H}-\mathrm{NMR}$ analysis results of carboxymethyl chitosan synthesized (Figure 7) shows a shift down field when compared to ${ }^{1} \mathrm{H}-\mathrm{NMR}$ spectra of standard chitosan that are on chemical peak $(\delta)$ $2.235 \mathrm{ppm}$ which is the acetyl spectra, chemical shift at $3.345 \mathrm{ppm}$ indicating $\mathrm{C} 2$ proton spectra of the glucosamine ring unit and the shift from 4.1 to $4.3 \mathrm{ppm}$ which is a proton spectra of $\mathrm{C} 3, \mathrm{C} 4, \mathrm{C} 5$, and $\mathrm{C} 6$ glucosamine ring units. The shift occurrs as a result of substitution of carboxymethyl groups in chitosan. In addition, the emergence of the peak at 3.902 to $3.986 \mathrm{ppm}$ indicate that the protons of the carboxymethyl substituted onto amino group $\left(\mathrm{N}\left(\mathrm{CH}_{2} \mathrm{COOH}\right)_{2}\right)$, the data was supported by the emergence of a peak at 4.7 to $5.5 \mathrm{ppm}$ indicating proton at $\mathrm{C} 1$ of $\mathrm{N}, \mathrm{N}$ - of carboxymethyl chitosan [8]. The emergence of the peak at $4.078 \mathrm{ppm}$ chemical shift also shows the proton of carboxymethyl substituted on the hydroxyl group on $\mathrm{C} 6$ [9].

Before etherification reaction, the ${ }^{13} \mathrm{C}-\mathrm{NMR}$ shows signals at $177.9 \mathrm{ppm}$ and at $25 \mathrm{ppm}$, which are assigned to the carbonyl carbon and the methyl carbon, respectively. The signal at $101.3 \mathrm{ppm}$ is assigned to the hydrogen bonded to carbon $\mathrm{C} 1$ of chitosan and the signals in 59.6 ppm, $73.1 \mathrm{ppm}, 81.1 \mathrm{ppm}, 78.6 \mathrm{ppm}$ and $64 \mathrm{ppm}$ are assigned to carbons $\mathrm{C} 2, \mathrm{C} 3, \mathrm{C} 4, \mathrm{C} 5$ and $\mathrm{C} 6$ of glypyranose, respectively.

After etherification reaction, ${ }^{13} \mathrm{C}-\mathrm{NMR}$ spectra of carboxymethyl chitosan synthesized can be seen in Figure 8. The spectrum shows the presence of new peaks compared to ${ }^{13} \mathrm{C}-\mathrm{NMR}$ chemical spectrum of standard chitosan that are on the chemical shift $(\delta)$ of 177.5 and $55.9 \mathrm{ppm}$, each of which is spectra of carbon of the carbonyl $(\mathrm{C}=\mathrm{O})$ and carbon of methylene $\left(-\mathrm{CH}_{2}-\right)$ of the carboxymethyl group. Methylene group carbon $\left(-\mathrm{CH}_{2}-\right)$ of the carboxymethyl group attached to the amine groups and hydroxyl each chemical appears on the chemical shift of
$57.4 \mathrm{ppm}$ and $53 \mathrm{ppm}$ [4]. The substitution of carboxymethyl groups in chitosan also lead to a shift of the peak at $173.4 \mathrm{ppm}$ and $48.8 \mathrm{ppm}$, each of which is a carbonyl carbon and spectra of the methyl carbon of $\mathrm{COCH}_{3}$ groups that are not deacetylated. Chemical shifts also occurs at $97.6 \mathrm{ppm}, 70.2 \mathrm{ppm}, 74.8 \mathrm{ppm}$ and $60.0 \mathrm{ppm}$ respectively show peaks of carbon $\mathrm{C} 1, \mathrm{C} 6, \mathrm{C} 3$, and $\mathrm{C} 2$ of the glucosamine ring, while peaks of $\mathrm{C} 4$ and $\mathrm{C} 5$ are overlapping at $76.4 \mathrm{ppm}$ chemical shift. Based on data from the analysis of FTIR, ${ }^{1} \mathrm{H}-\mathrm{NMR}$ and ${ }^{13} \mathrm{C}-\mathrm{NMR}$ can be concluded that the products synthesized in this study was carboxymethyl chitosan with carboxymethylation occur in the substituted amine groups and hydroxyl groups of chitosan.

\section{Water Content of Carboxymethyl Chitosan}

Water content of the high solubility carboxymethyl chitosan is up to $14.28 \%$. This value is higher than the water content of the chitosan that is up to $8.2 \%$. The high water content suggests that carboxymethyl chitosan is hygroscopic and has stronger ability to bind with water than chitosan itself. The high ability of is because carboxymethyl chitosan have carboxylic groups capable of forming hydrogen bond between carboxymethyl chitosan with water molecules. This causes the hydrated water molecules that surround the chain of carboxymethyl chitosan are more than that surrounding the chitosan chains. In addition, the high water content also depends on the humidity level around the storage area of carboxymethyl chitosan and chitosan.

\section{Ash Content of Carboxymethyl Chitosan}

The results on high solubility carboxymethyl chitosan shows the ash content of $8.48 \%$. 
Carboxymethylchitosan ash content value is greater than the ash content of the chitosan that is $0.06 \%$. This values show that the mineral content of the synthetic carboxymethyl chitosan is higher than chitosan. The increasing value of ash content in carboxymethyl chitosan may be due to the washing process using methanol was still leaving minerals salts such as $\mathrm{NaCl}$ and $\mathrm{NaCO}_{3}$ which are by products of chitosan.

\section{Molecular Weight of Carboxymethyl Chitosan}

Carboxymethyl chitosan molecular weight value is one of the characteristics that indicate the magnitude of the degree of polymerization of carboxymethyl chitosan. The analysis shows that the molecular weight of high solubility carboxymethyl chitosan $\left(2.86979 \times 10^{5} \mathrm{~g} / \mathrm{mol}\right)$ is smaller than the molecular weight of chitosan $\left(6.5483 \times 10^{5} \mathrm{~g} / \mathrm{mol}\right)$. The use of high temperature and lengthy synthesis time for 4 hours allows the termination of polymer bonding (depolymerization) of carboxymethyl chitosan chains resulting in lower carboxymethyl chitosan molecular weight.

\section{Swelling Effect}

The affinity of polymeric hydrogels for solvents can be easily determined by their sorption ability. The swelling process of polymers involves the diffusion of the liquid phase into the hydrogel bulk, which is possible by the mobility of the polymeric chains and the free-volume among chains. The molecules of the liquid remain entrapped in these free spaces up to an equilibrium point, as determined by both polymer solvent interactions and the elasticity of the hydrogel [5].

The result shows that the swelling value of carboxymethyl chitosan is greater than the swelling value of chitosan, $884.19 \%$ to $365.19 \%$, respectively. The high swelling value of carboxymethyl chitosan is probably due to the dissociation of carboxylic groups, thus increasing the osmotic pressure in the hydrogel which results in an increase in the swelling value of carboxymethyl chitosan. According to previous study [10], the swelling value in water is highly dependent on the osmotic pressure difference between the inner part of the gel and the environment caused by the redistribution of the free ions. When the concentration of the free ions in the hydrogel is lower than the surrounding conditions, the osmotic pressure of the environment causes the hydrogel to shrink, on the contrary, the greater osmotic pressure within the hydrogel causes the hydrogel to swell [11].

\section{CONCLUSION}

The optimum synthesis conditions carboxymethyl chitosan obtained in this study at the use of $40 \%(\mathrm{w} / \mathrm{v})$ $\mathrm{NaOH}$ concentration for alkalizing chitosan, chitosan to monochloroacetic acid ratio of 1: 7, and temperature and reaction time at $80^{\circ} \mathrm{C}$ for 4 hours, respectively.

Carboxymethyl chitosan with the highest solubility has the properties of solubility in water, ash content, water content, molecular weight, porosity, and swelling effects, that are $63.78 \mathrm{mg} / \mathrm{mL}, 8.48 \%, 14.27 \%, 2.86978 \times 10^{5} \mathrm{~g} / \mathrm{mol}$, $75.69 \%$ and $884.19 \%$, respectively.

\section{ACKNOWLEDGMENT}

The financial support provided by the Directorat General of Higher Education, Ministry of National Education and Culture Indonesia through the Competitive Grant DIPA UNSOED No 64/UN23.10/PN/2013 is gratefully acknowledged.

\section{REFERENCES}

[1] Sorokin A. B., Quignard F., Valentin R., Mangematin S., Appl. Catal., A, 309 (2006) 162.

[2] El-Hefian E. A., Elgannoudi E. S., Mainal A., Yahaya A. H., Turk. J. Chem., 34 (2010) 47.

[3] Ketkangplu P., Phromdetphaiboon and Unob F., J. Sci. Res. Chula. Univ., 30 (1) (2005) 87.

[4] Abreu F. R. and Campana-Filho S. P., Polímeros: Ciência e Tecnologia, 15 (2) (2005) 79.

[5] Farag R. K. and Mohamed R. R., Molecules, 18 (2013) 190.

[6] Basmal, J., Prasetyo A. danFawzya Y.N., JurnalPenelitianPerikanan Indonesia, 11 (8) (2005) 1.

[7] Mourya V. K., Inamdar N. N. and Tiwarki A., Adv. Mat.Lett., 1 (1) (2010) 11.

[8] An N.T., Thien D.T., Dong N.T., and Dung P.L, Carbohydr. Polym., 75 (2009) 489.

[9] Liu, X., Fan Y., Tao S., Anrong Z., Qi Wang, Zhong Sun, and Jun Shen, J. Agric. Food. Chem., 59 (2011) 10683.

[10] Yadav, H. K. S, and H. G. Shivakumar, 2012, International Scholarly Research Network, ISRN Pharmaceutics, ID 763127, 9 pages.

[11] Guo, B., Jinfang Y., Li Y., and Qingyu G.,Colloid.Polym. Sci., 285 (2007) 667. 